\title{
Evolution of the reinforced I-beam strain state
}

\author{
Artem Ustinov ${ }^{1, *}$, Anatolij Klopotov ${ }^{1,2}$, Aleksandr Potekaev ${ }^{2}$, Vasilij Plevkov ${ }^{1}$, and \\ Ekaterina Marchenko ${ }^{2}$ \\ ${ }^{1}$ Tomsk State University of Architecture and Building, 634003 Tomsk, Russia \\ ${ }^{2}$ National Research Tomsk State University, 634050 Tomsk, Russia
}

\begin{abstract}
The paper presents experimental results of the strain state evolution of the steel I-beam reinforced with composite material under four-point bending loading. Digital image correlation technique was used to trace the evolution of plastic strain zones distribution. The images of longitudinal relative strain on the lateral surface of the reinforced I-beam web were obtained and analyzed. It was found that the increase of loadbearing capacity of the reinforced beams can exceed $26 \%$.
\end{abstract}

\section{Introduction}

The given work presents experimental data on the strain distribution evolution on the surface of the I-beam web without reinforcement and with external reinforcement by carbon fiber under four-point bending.

The real life environment can generate critical conditions for structural elements being exposed to external loads. This state of structural elements is characterized by plastic strain, which in case of emergency results in structural failure. Thus, the mechanisms leading to failure of both structural elements and the systems of external reinforcement are required to be specified.

Digital image correlation technique provides the possibility to receive information in situ about deformation processes on the surface.

When the mentioned technique is applied for investigation of strain impacts on the samples of various geometric shape it makes possible to reveal the common factors required for operation of structure under conditions of ultimate external loads.

The peculiar features attributed to conducting of such experimental studies were previously described in a number of research works [1-5]. Evolutions of plastic strain core areas distribution on the surface of solid bodies under various impacts in various structures are being actively studied nowadays [5-7].

Strain alterations on the surface of solid bodies occur on different structural levels, corresponding to strain mechanisms. Plastic strain is characterized by appearing spatiallytemporal hierarchy of structures and phenomena. The basic strain and strengthening mechanisms refer to micro- and meso-structural level of solid bodies strain [8 -9].

Adhesive connections in foreign practice are used in reinforcing and restoring steel structures as an alternative to traditional connecting methods, such as bolted, welded,

* Corresponding author: artemustinov@bk.ru 
riveted connections. Thus, the negative aspects of these methods, such as increase of constant load, complexity of work, etc., can be diminished. Experimental and theoretical studies of load-bearing capacity recovery in respect of defective steel structures working in bending reinforced with carbon fiber were conducted by many foreign scientists [11-17].

\section{Materials and methods}

Experimental testing was conducted at the Research and Education Center "Testing Building Materials and Structures" in Tomsk State University of Architecture and Building (Tomsk, Russia).

The I-beam was produced from steel with yield stress $\sigma_{\mathrm{y}}=225 \mathrm{MPa}$, ultimate strength $\sigma_{\mathrm{u}}=360 \mathrm{MPa}$. The height of the beam cross section is $160 \mathrm{~mm}$, the flange width $-82 \mathrm{~mm}$, the flange thickness $-7.4 \mathrm{~mm}$, the web thickness $-5 \mathrm{~mm}$, the total length $-1800 \mathrm{~mm}$, the span between the centers of supports $-1700 \mathrm{~mm}$.

Adhesive used for bonding of the reinforcement elements was FibARM Laminate+; it has shear strength $>13 \mathrm{MPa}$ while the thickness of the layer is $1 \mathrm{~mm}$. The external element which is being reinforced is made from carbon fiber lamella FibARM Lamel 12-50. Its tensile strength is $>2800 \mathrm{MPa}$. The thickness of lamella is $1.2 \mathrm{~mm}$; its width is $82 \mathrm{~mm}$, which is defined by the flange width of the I-beam.

The surface of the I-beam web was cleaned by mechanical method using rotating wire brushes. Then, the sample was cleaned from dust and degreased.

The area under study was colored in two layers. The first layer was the base of white color; the second layer was single-point coloring. The wall coloring was performed to measure displacements and the strain on the surface of sample using Vic-3D facility. This system is intended for recording and analysis of stereoscopic speckle images and obtaining the data on spatial straining of the sample surface. The selected methodology enables to obtain the data on spatial straining of the whole area under study. The traditional strain gauge measurements in their turn can only provide local measurements of one strain component restricted in length of measurements. The scheme of recording the evolution of deformation distribution on the lateral surface of the I-beam under study is illustrated in Figure 1.

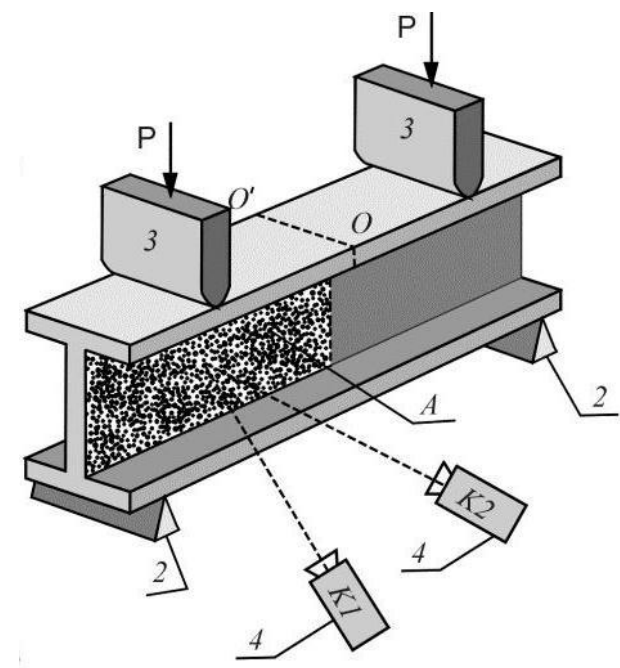

Fig. 1. The scheme of recording the images of the I-beam lateral surface. 1 - I-beam; 2 - supports; 3 -indenter; 4 - digital cameras $\mathrm{C} 1$ and $\mathrm{C} 2$; $\mathrm{A}$ - the area under study; OO' - the axis line passing through the center of the I-beam; $\mathrm{P}-$ the applied load. 
Bending tests were conducted on a universal testing machine UTM 4500 (GTCS, USA) with maximum strength $4500 \mathrm{kN}$ (458 tf). The loading was carried out at a constant rate of $160(1 / \mathrm{s})$.

The algorithm of bending tests of the I-beams is given below. The sample was placed on supporting points. One of the supports was hinged-fixed providing only the sample turning; the other was hinged-non-fixed, providing not only the sample turning but also its displacement in the plane of bending. In order to prevent the flange local buckling the steel plates possessing high bending stiffness were mounted above the supports. The load on the sample was transmitted from the testing machine through steel traverse. The traverse transferring load on the tested sample through two hinged supports was mounted on the sample centrally. The scheme of elements location is presented in Figure 2.

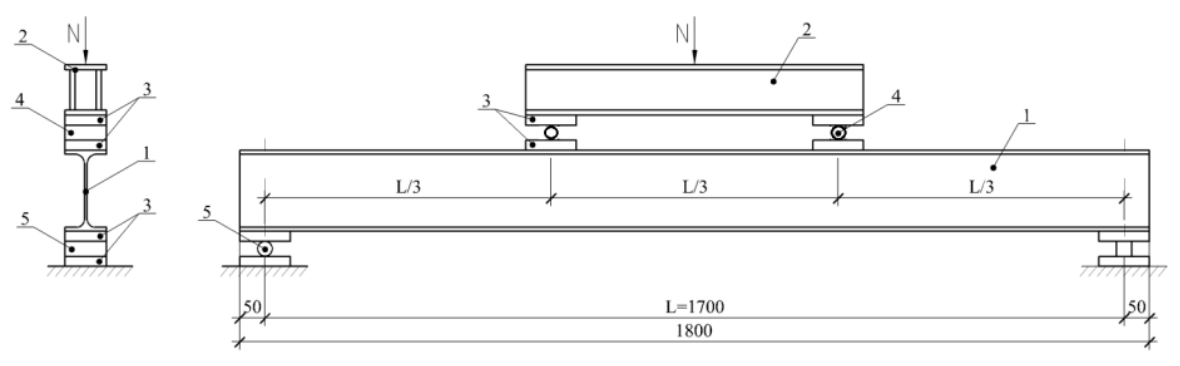

Fig. 2. Loading system for testing of I-beams under four-point bending. 1 - I-beam; 2 - traverse; 3 distributing plates; 4 - hinged-fixed support; 5 - hinged-non-fixed support.

\section{Results and discussion}

Figure 3 presents the strain diagrams in the coordinates " $\mathrm{P}-\mathrm{f}$ " obtained resulting from bending tests of the reference and reinforced I-beams. Four stages can be observed on the strain diagram of the reference I-beam. The first stage (the interval OA) is characterized by linear nature and corresponds to the elastic stage of material straining. The second stage (the interval $\mathrm{AB}$ ) - is a transition stage which is characterized by the beginning of elastoplastic straining. The third stage (the interval BC) at the strain curve "loading-deflection" is conditioned by the peculiar features of the type of external load applied to the I-beam. In this case transition to the third stage is conditioned by the slow flange buckling of the Ibeam below the area where the load is applied. The fourth stage (the interval CD) - the total loss of system stability during testing.

In the point $\mathrm{C}^{\prime}$ of the strain diagram "P-f" of I-beam deflection the experiment was stopped as the system generally loses its stability (Fig. 3, curve 2).

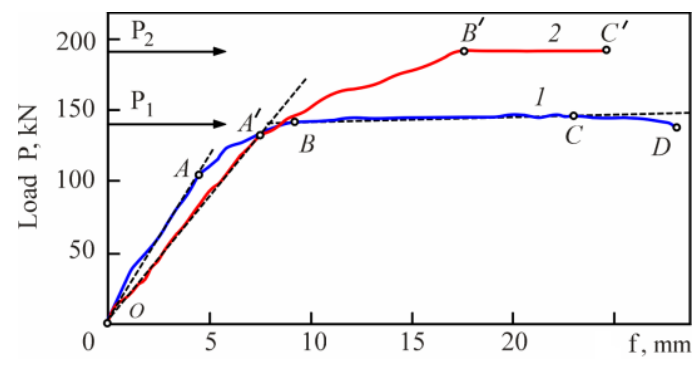

Fig. 3. The diagrams "load-deflection" of the I-beam without reinforcement (curve 1) and the I-beam reinforced with carbon fiber in the top and bottom flange (curve 2) 


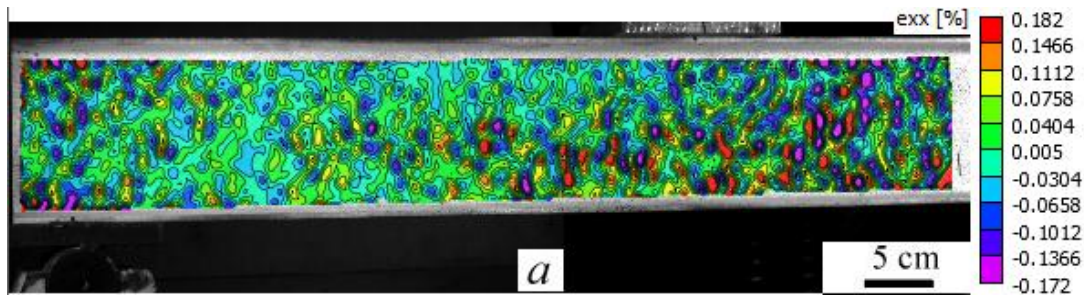

$\mathrm{P}=39.2 \mathrm{kN}$,

$\mathrm{f}=1.6 \mathrm{~mm}$

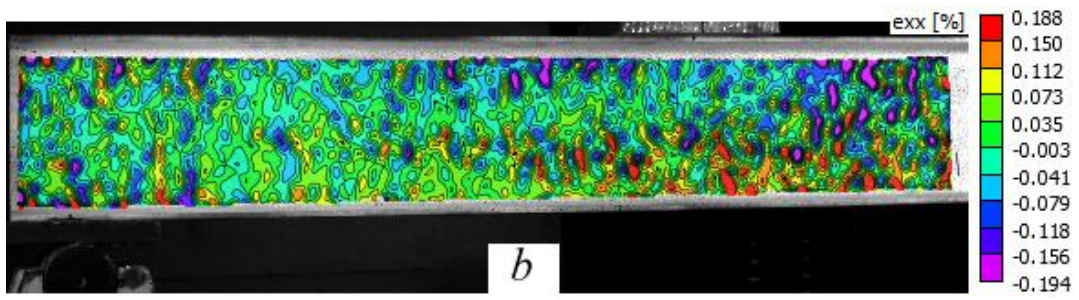

$\mathrm{P}=80.8 \mathrm{kN}$,

$\mathrm{f}=3.4 \mathrm{~mm}$

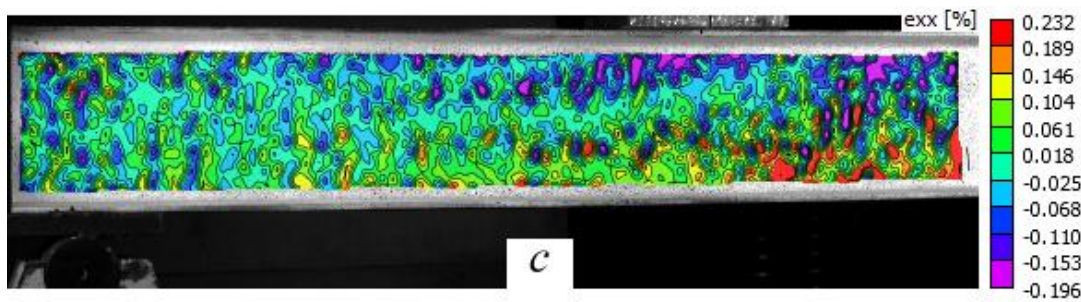

$\mathrm{P}=117.7 \mathrm{kN}$,

$\mathrm{f}=5.4 \mathrm{~mm}$

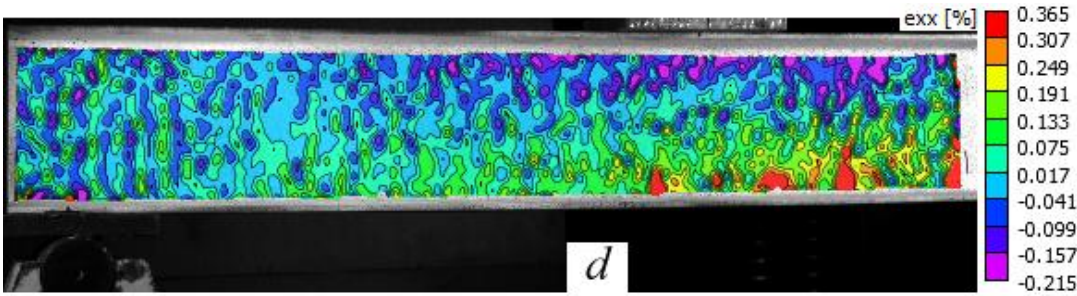

$\mathrm{P}=132.4 \mathrm{kN}$, $\mathrm{f}=7.9 \mathrm{~mm}$
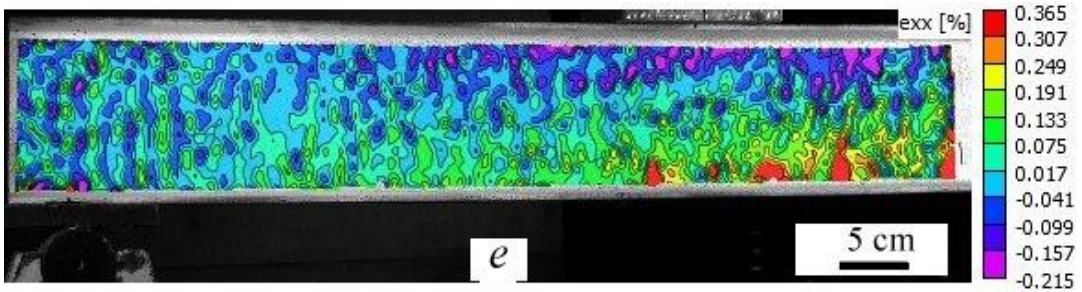

$\mathrm{P}=140.3 \mathrm{kN}$, $\mathrm{f}=9.1 \mathrm{~mm}$

Fig. 4. The images of longitudinal relative strain of the reference steel I-beam under various loads.

The distribution of local strain zones on the lateral web of the reference I-beam at the load $\sim 40 \mathrm{kN}$ demonstrates chaotic nature of the cores distribution which corresponds to the first stage (Fig. 4a). Plastic strain zones of compression and tension locate chaotically in regards to each other in the central part of the I-beam. Plastic strain zones defined in accordance with the mentioned methods mostly possess the shape of an ellipse elongated along the applied load (perpendicular to the top and bottom planes of the I-beam). At the same time, the local strain areas are of the average sizes from 2 to $10 \mathrm{~mm}$. Along with the 
increase of the load the image of the local strain zones distribution changes. Depending on the strain the local strain zones in the central part of the beam are located in the following way: compression zones are in the top part, while tension zones are in the bottom part (P. $\sim 80 \mathrm{kN}$, Fig. $4 b)$.

During transition from the first stage to the second local strain zones distribution changes significantly. The separate local strain zones start to merge into larger zones which are elongated along the applied load (Fig. 1 and Fig. $4 c-e$ ). In this case, local strain zones initiate in the top and bottom lateral surface in the central part of the I-beam accordingly, depending on the strain type. In this case, local strain zones are surrounded by the areas with lower values of strain, but of the same type. The other image of the local strain zones distribution is observed in the end of the I-beam where the hinged-fixed support is located (Fig. 2). The local strain zones in this area are located in layers (Fig. 4,c-e); the layers of compression zones elongated along the load direction interchange with the tension zones on the beam surface.

The diagram "P-f" (Fig. 3) illustrates the ultimate load $\left(\mathrm{P}_{1 .} \sim 140 \mathrm{kN}\right)$ with an arrow. After reaching the mentioned load the process of buckling failure occurs with the reference I-beam flange below the area of the applied load (transition to the third stage). Fig. $4 e$ demonstrates the image of longitudinal relative strain distribution.

The image of longitudinal relative strain distribution of the reference I-beam flange under ultimate load $\left(\mathrm{P}_{1}\right)$ shows wave-like behavior of plastic strain zones distribution (Fig. $4 c-e$ ). Along with that, in the top part of the I-beam lateral surface the maximum value of compressive plastic strain in local plastic strain zones reaches the values of $0.215 \%$. At the same time, in the bottom part of the I-beam lateral surface the maximum value of tensile plastic strain in local strain zones is larger than in the top part of the lateral surface (it reaches the values of $\sim 0.36 \%$ ).

The other image of longitudinal relative strain distribution at the same external load applied is observed on the lateral web of the reinforced I-beam (Fig. 5). The local strain zones with high compressive strain values are basically located on the top plane in the central part of the I-beam at the load P $\sim 40 \mathrm{kN}$ (Fig. $5 a$ ). Along with the increase of applied load but within the range of the first stage $(\mathrm{P} \sim 80 \mathrm{kN})$ the density of local strain zones with high values of compressive strain increases on the lateral web of the reinforced I-beam in its top part. In the bottom part of the lateral beam surface the decrease in density of local compressive strain zones is observed (Fig. $5 b$ ).

During transition from the first stage to the second in the central part of the I-beam surface plastic strain zones in the middle part are also observed. However, the distribution of strain zones in the area of the I-beam end behaves the other way as compared to the case of the reference I-beam.

Strain zones distribution in the end of the I-beam has its own nature. There are no clearly distinguished local strain zones. There are strain zones which are significant in size with low values of strain and they are elongated along the action of the applied load (Fig. $5 b$ ). The expansion deformation occurs in these zones, they interchange as the layers: strain zone with the values $0.005 \%$, and its neighboring strain zone with higher values $(\sim 0.092 \%)$.

The diagram "P-f" (Fig. 3) shows the ultimate load of the reinforced I-beam with an arrow $\left(\mathrm{P}_{2 .} \sim 190 \mathrm{kN}\right)$. After reaching the mentioned load the process of buckling failure of the flange occurs below the location of applied load (transition to the third stage). However, the zones on the top and bottom parts of the I-beam lateral surface which are occupied by local strain zones with the maximum values are significantly lower than in the reference Ibeam with the same values of the applied load. Also, the density of local strain zones location is significantly lower. 


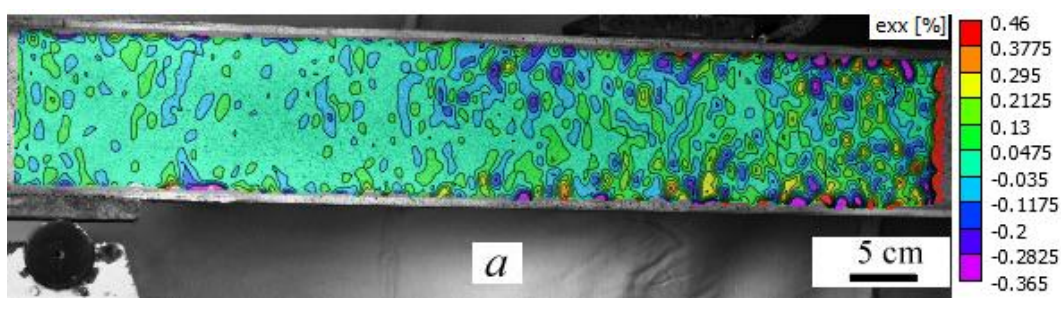

$\mathrm{P}=39.8 \mathrm{kN}$,

$\mathrm{f}=2.1 \mathrm{~mm}$
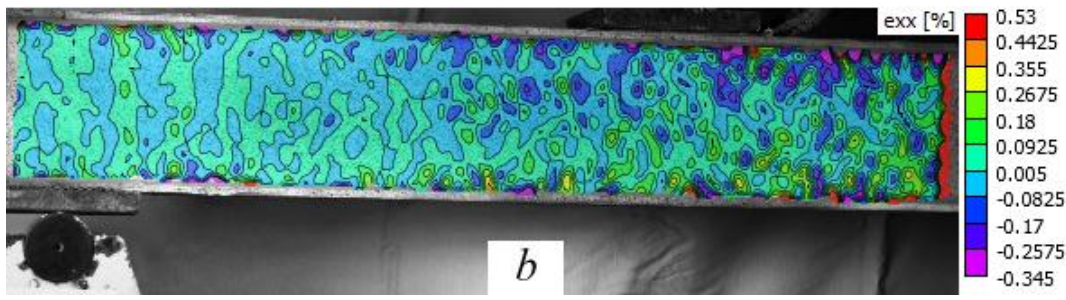

$\mathrm{P}=80.2 \mathrm{kN}$,

$\mathrm{f}=4.4 \mathrm{~mm}$

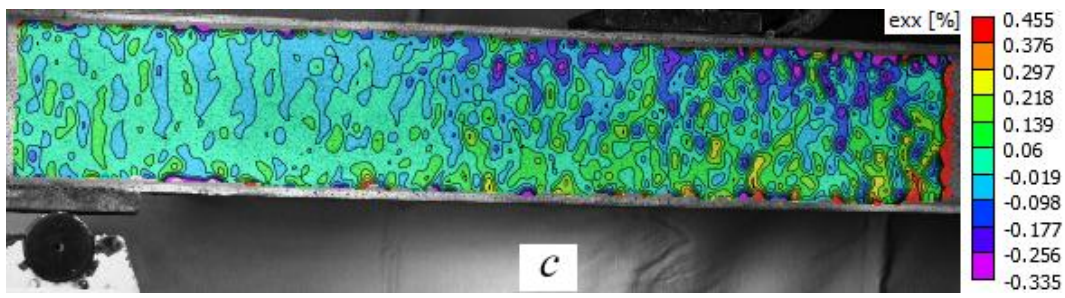

$\mathrm{P}=117.1 \mathrm{kN}$,

$\mathrm{f}=6.4 \mathrm{~mm}$

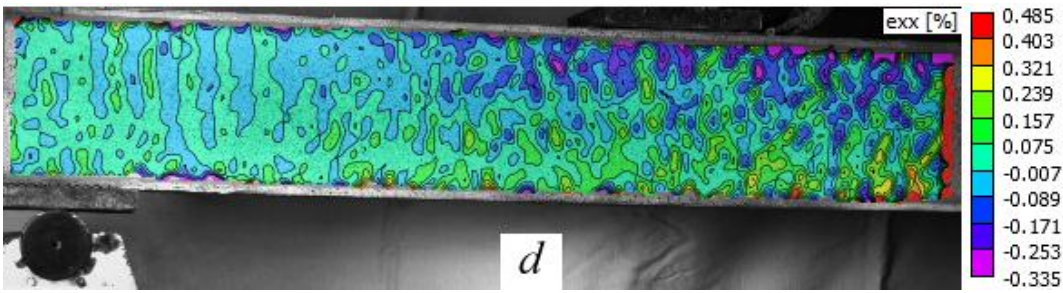

$\mathrm{P}=132.4 \mathrm{kN}$, $\mathrm{f}=7.2 \mathrm{~mm}$

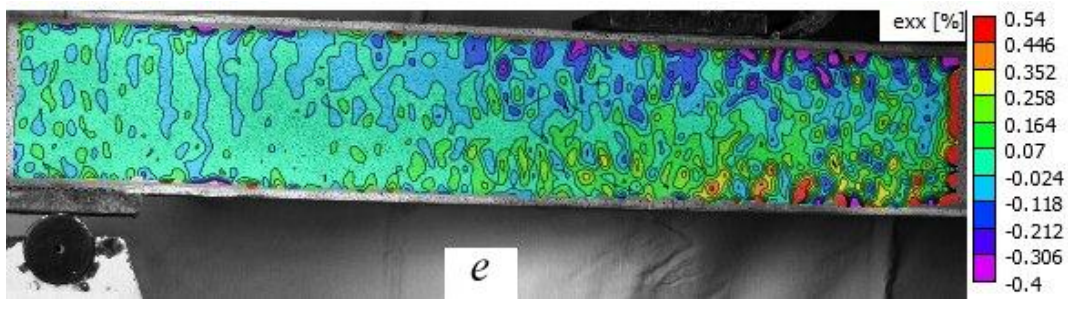

$\mathrm{P}=140.2 \mathrm{kN}$, $\mathrm{f}=8.5 \mathrm{~mm}$

Fig. 5. The images of longitudinal relative strain of the steel I-beam web reinforced with carbon fiber lamellas glued to the top and bottom flanges of the beam under various loads.

\section{Conclusion}

Based on the conducted research the following conclusions can be made.

1. On the strain diagrams in the coordinates " $\mathrm{P}-\mathrm{f}$ " during testing of the reference Ibeams and the I-beams reinforced with carbon fiber lamellas the four stages can be distinguished: the first stage is characterized by the linear dependency and elastic strain of the material; the second stage is the transition stage, it is characterized by the initiation of 
the plastic strain in the areas which are the most strained; the third stage is conditioned by the slow buckling failure of the I-beam flange below the area of the applied load; the fourth stage reflects structural failure (the loading system and the beam) during the process of testing and it is defined not by mechanical properties of the material but by the structure itself and the type of strain impact.

2. It was defined that the ultimate load of the I-beams reinforced with carbon fiber lamellas equals to $190 \mathrm{kN}$; that is the load that initiates the process of buckling failure of the reinforced I-beam top flange; and that value is by $26 \%$ more than for the reference Ibeam.

3. It was established that on the reference and the reinforced I-beams the distribution of strain zones and local plastic strain core areas on the lateral planes evolve in a different manner under bending at the same external actions.

The obtained data can be used during reinforcement of the operating steel structures which are subjected to static loads. Application of carbon fiber will enable to extend the operation lifetime of the steel structures, to increase their load-bearing capacity in case of increasing the design loads, and to recover the load-bearing capacity of defect elements.

The scheme of the steel I-beams reinforcement with carbon fiber in the area of maximum normal stresses contributed to the increase in load-bearing capacity by a quarter. The application area of the elaborated reinforcement type is restricted by the fact that temporary load on beams should be excluded.

Introduction of composite materials provides good technical and economic perspectives in case of reinforcing the linear structural elements of buildings and structures under operation.

\section{References}

1. V. Vildeman, T. Tretyakova, M. Tretyakov, Journal of Machinery Manufacture and Reliability 5, 106 (2010) (in Russian)

2. D. Kopanitsa, A. Ustinov, A. Potekaev, A. Klopotov, G. Kopanitsa, AIP Conf. Proc. 1698, 030014 (2016)

3. A. Potekaev, A. Klopotov, AIP Conf. Proc. 1683, 020233 (2015)

4. A.M. Ustinov, D.G. Kopaniza, Y.A. Abzaev, A.A. Klopotov, B.O. Koshko, G.D. Kopaniza, AIP Conf. Proc. 1800, 040007 (2017)

5. A.F. Ioffe, Fizika kristallov [Physics of crystals] (OGIZ, Moscow, Leningrad, 1929) (in Russian)

6. V.P. Alekhin, Fizika prochnosti $i$ plastichnosti poverhnostnyh sloev materialov [Physics of Strength and Plasticity of Surface Layers in Materials] (Nauka, Moscow, 1983) (in Russian)

7. V.S. Ivanova, Sinergetika. Prochnost' $i$ razrushenie metallicheskih materialov [Synergetics. Strength and fracture of metallic materials] (Nauka, Moscow, 1992) (in Russian)

8. V. Panin, V. Fomin, V. Titov, Physical Mesomechanics 6(2), 5 (2003) (in Russian)

9. V. Panin, Physical Mesomechanics 2(6), 5 (1999) (in Russian)

10. M. Tavakkolizadeh, H. Saadatmanesh, J. Struct. Eng1. 129(2), 186-196 (2003)

11. A. Taoum, H. Jiao, D. Holloway, International Journal of Steel Structures 15(1), 125 $134(2015)$

12. S.S.J. Moy, A.G. Bloodworth, Structures \& Buildings 160, 81-93 (2007)

13. M. Elchalakani, D. Fernando, Thin-Walled Structures 53, 58-71 (2012)

14. Y.J. Kim, J. LaBere, I. Yoshitake, Composites: Part B 51, 233-245 (2013)

15. K.M. El-Sayed, N.N. Khalil, I.M. El-Shennawy, International Journal of Advanced Engineering, Management and Science 2(1), 9-17 (2016) 
16. E.Y. Sayed-Ahmed, Advanced Composite Materials in Bridges and Structures IV, 1-8 (2015)

17. M.H. Seleem, I.A. Sharaky, H.E.M. Sallam, Materials and Design 31, 1317-1324 (2010) 